\section{Rocket company to sell insurance?}

ARIANESPACE, the company responsible for commercial exploitation of the European space launcher Ariane, is working out a scheme to offer its customers partial insurance against the risk of failure. This development is a response to the rising cost of satellite insurance on the open market, which may now be as much as 30 per cent of the capital cost of a satellite.

Arianespace plans to offer insurance against the risk that satellites will be lost during the launch period. Satellite operators will have to arrange separate insurance against the risk of failure of the payload, which includes not only the satellite but the rocket motor by means of which the satellite is transferred into its final orbit from the apogee of the highly elliptical injection orbit.

Under the insurance plans, the company would charge users a standard premium based on the risk of failure spread over as many as 15 launches in a three-year period. Arianespace would protect itself in the commercial reinsurance market. Before the failure of last month's launch of Ariane, insurance premiums were running at 18-20 per cent of satellite costs, of which $10-12$ per cent is estimated to have covered launch failure and 7-8 per cent the risk of satellite failure. Ariane users will have to cover the second risk independently. Arianespace says that it is still negotiating with insurers and so does not yet know what premiums it will charge.

The scheme may nevertheless be ready in time for the planned launch of the French Earth observation satellite SPOT 1, perhaps two months from now, but Arianespace is more concerned with the string of commercial users that have booked into succeeding flights. It thinks that attempts to charge them insurance premiums up to 30 per cent of capital costs are "completely stupid", but is also clearly alarmed about the effect on the long-term demand for launching services.

A successful launch insurance scheme with modest premiums, on the other hand, should give Ariane an advantage in competition with the US shuttle. In France, there is much resentment at reports that charges for shuttle flights are often only 20 per cent of real costs. Ariane's advantage over the shuttle is that much less rocket power is needed to transfer a satellite to geostationary orbit from the apogee of the injection orbit than from the low-altitude circular orbit of the shuttle, with the consequence that the risks of failure must be less.

Meanwhile, the failure of Ariane's fifteenth launch on 13 September has been explained by an independent commission of inquiry. Arianespace technical director, Dr Klaus Iserland, said last week that the chief problem appears to have been a leak in a valve between the liquid-hydrogen tank of Ariane's third stage and the combustion chamber; the leak has been traced to an extra flange, designed to make the liquid-hydrogen valve fit more tightly, which was added in the eighth Ariane flight. The valve's differential expansion allows it to leak at intermediate temperatures, and in particular when it is being cooled by the first flow of liquid hydrogen.

Arianespace has now asked the manufacturers to remove the extra flange. The "earliest possible hypothetical date" for the next launch, according to Iserland, is mid-December. If Arianespace can hold to that, SPOT 1 will be only one month late.

Robert Walgate

\section{Skull-trade ban}

\section{New Delhi}

INDIA, which prohibited export of rhesus monkeys for medical research, has now banned the export of skulls and skeletons for medical colleges abroad. The ban follows shocking reports in the Indian press about children being kidnapped and killed for their skulls.

The article in the Pataliputra Times (owned by Dr Jagannath Misra, former chief minister of Bihar) claimed that traders in skulls and skeletons in Bihar receive children from gangs of kidnappers who are paid $£ 35$ to $£ 70$ per child. It said that the children are handed over to head-choppers at Bansghat on the bank of the Ganges who charge $\mathfrak{£} 2$ for chopping a head. The headless bodies are thrown into the Ganges while the heads are stripped of skin, boiled and bleached for export. The report claimed that 1,500 skulls processed this way are sent to Calcutta each month by rail for export to 23 countries. The article claimed that 5,000 to 7,000 children are reported missing every year in the state.

These revelations created a furore in the Bihar state legislative assembly. The police arrested a man suspected of being a kingpin of the trade, but he was released on bail. The state government however said that skulls found in three boxes meant for export probably belonged to dead bodies floating in the Ganges. It is a fact that poor Hindus who have no money to buy firewood for cremating the dead simply throw the bodies in the river.

The skull trade dates back to 1936. A ban on skeleton export imposed in 1976 was lifted in 1977 when there was a change in the central government. Since then India has reportedly been meeting 80 per cent of the world's requirement of skulls and skeletons with Bihar alone contributing 60 per cent. Thirteen companies in Calcutta had licences for export as of August this year, when the government imposed a fresh ban. K. S. Jayaraman
US space science Two paths to
leadership?

Washington

SHould US space science be concentrated on a few large projects, or instead be spread more widely? Congress heard both views last week, at a committee meeting looking ahead to financial year 1987, which is still a full year off. The National Aeronautics and Space Administration (NASA), according to Noel Hinners, director of the Goddard Space Flight Center, has as a top priority the creation of "a set of long-life space observatories complemented by ground-based facilities". The space shuttle makes this plan feasible by permitting the repair, maintenance and improvement of instrumentation satellites. The delayed Hubble space telescope, now due to be launched next year, is the first of these planned observatories, and will be followed by the gammaray observatory in 1987 . The solar optical telescope and the space infrared telescope facility, programmes originally recommended by US astronomers in 1972, have been "seriously delayed", but are still planned for the 1990 s if Congress will pay for them.

Hinners also wants Congress to allocate funds for the advanced X-ray astrophysics facility programme, planned for a 1987 start but likely to be postponed when next year's appropriation is decided in mid1986. Since the Einstein observatory went out of action, European and Japanese groups have taken the lead in this field, according to Jeffrey Hoffman of NASA. He says that Congress must approve the programme soon if the United States is to regain its supremacy in X-ray astronomy. Another project waiting on Congress is the large deployable far-infrared detector, which NASA hopes to launch towards the end of the 1990s. James Van Allen of the University of Iowa is on the other side of the argument. Van Allen was one of the first users of the US vanguard satellites in the $1950 \mathrm{~s}$, when he discovered the clouds of charged particles trapped in the geomagnetic field. He wants NASA to spend less on major programmes and to increase its budget for smaller, flexible and potentially more productive projects involving more laboratories.

There was no shortage of proposals for such programmes last week. One was the international solar terrestrial physics programme and another an Earth observing system to coordinate data collection on climate, geography and chemistry. But NASA is assured of only one per cent per year budgetary growth, which means, says Van Allen, that space science and applications are likely to experience "hard times . . . for many more years as planned expenditures for the space station increase" 